\title{
Desigualdade e a indiferença com a pobreza*
}

\section{Inequality and the indifference with the poverty}

\author{
Carlos Alberto Batista Maciel ${ }^{2}$
}

MACIEL, C. A. B. Desigualdade e a indiferença com a pobreza. Rev. Ter. Ocup. Univ. São Paulo, v. 19, n. 1, p. 1-11, jan./abr. 2008.

RESUMO: Este texto discute sobre o processo de aprendizagem do comportamento social da indiferença com a pobreza em um contexto de desigualdade social. Considera a pobreza como um fenômeno social construído historicamente que tem expressões objetivas e subjetivas. Adota especialmente as reflexões de Pierre Bourdieu e de Jessé Souza sobre habitus para a construção da análise produzida acerca da institucionalização da indiferença da pobreza.

DESCRITORES: Desigualdade social. Pobreza.Hábitos.

\section{INTRODUÇÃO}

pobreza é uma das faces pela qual a desigual-
dade social se manifesta, portanto não é um
fenômeno atemporal, moral ou natural. É antes de tudo o resultado direto de um processo que se manifesta objetiva e subjetivamente na experiência de vida de milhões de pessoas em todo o mundo. Nessa experiência, a cultura dominante tende a cimentar uma visão social de mundo que distorce a capacidade de apreensão do fenômeno da pobreza. Isto porque os "conjuntos estruturados de valores, representações, idéias e orientações cognitivas" (LOWY, 1985, p.13) que formam a visão social de mundo hegemônica, tendem a estar em correspondência com a ordem social.

A cultura de indiferença com a pobreza, em particular, é ao mesmo tempo estruturada e estruturante. Estruturada, pois esta indiferença tem manifestações já estabelecidas e consolidadas que se manifestam por meio de expressões cotidianas de banalização com a vida humana e o descaso com sofrimento produzido pelo agravamento da vulnerabilidade social. Estruturante, pois essa cultura da indiferença é afirmada e reafirmada continuamente por meio de diversos processos de socialização em diferentes espaços sociais, por meio de práticas sociais, que expressam comportamentos absorvidos como normais e naturais.

\footnotetext{
* Este artigo foi organizado a partir das idéias apresentadas em uma Conferência proferida com o mesmo nome na $59^{\mathrm{a}}$ edição do Encontro Anual da Sociedade Brasileira para o Progresso da Ciência - SBPC ocorrido em Belém do Pará em 2007.

${ }^{2}$ Assistente Social, Mestre em Antropologia pela UFPA, Doutor em Sociologia pela Universidade Estadual Paulista - FCL / Araraquara e Professor da Graduação e da Pós-Graduação em Serviço Social da UFPA.

Endereço para correspondência: Centro de Docência e Pesquisa em Terapia Ocupacional da FMUSP. Rua Cipotânea, 51 - Cidade Universitária. 05508-900. São Paulo, SP.
} 
Assim sendo, pretendemos apresentar reflexões que poderão colaborar para a compreensão acerca da dança em que a indiferença com a pobreza é coreografada por pobres e ricos que concorrem com a reprodução desse comportamento social.

\section{Pobreza natural ou pobreza construída}

Sendo a pobreza um fenômeno social ela é a "síntese de múltiplas determinações". Portanto, é conseqüência direta do processo de exploração e expropriação do processo de produção econômica, em que o aumento da pobreza passa a ter significado explicativo na medida em que se desmonta a funcionalidade do sistema econômico que a gera. Não obstante, a pobreza como fenômeno social inquieta de diversas maneiras, seja porque ela evidencia o sistema econômico como fonte de desigualdade ou pelo fato de tornar-se um perigo constante frente a tênue ordem estabelecida.

$\mathrm{Na}$ luta das populações trabalhadoras pela garantia de melhores condições de vida e pelos seus direitos, a cidadania passa a ser parte constitutiva da relação existente entre a pobreza e suas formas de enfrentamento. A realização concreta desta relação contribui ou não para a formação e a garantia da cidadania dos indivíduos prisioneiros do domínio espacial da pobreza. Os objetivos e funções existentes nas formas de enfrentamento da pobreza, notadamente pelas políticas sociais, podem revelar interesses contraditórios subsumidos na complexa constituição da origem e das ações programáticas dos programas, serviços e projetos que materializam os direitos sociais da população vulnerabilizada.

Nessa perspectiva, o movimento de enfrentamento da pobreza é atravessado em toda a sua extensão por vetores ideológicos, políticos e econômicos.

[...] uma sociedade em que as classes trabalhadoras não são reconhecidas como sujeitos de interesses e direitos legítimos, uma sociedade em que os interesses populares não conseguem se fazer representar no plano do Estado, uma sociedade em que as maiorias não são e nunca foram levadas em conta na elaboração e execução de políticas econômicas, em que não existem partidos sólidos e consistentes capazes de dar expressão política às aspirações populares, em que os mecanismos normais de representação política não foram capazes de dissolver o prebendalismo que descaracterizam e desvirtuam políticas sociais (TELLES, 1992, p. 12).

Portanto, não basta dizer que determinada reivindicação social foi garantida para se afirmar que a cidadania da população está se realizando. É necessário ir mais avante, desmontando o complexo de vetores econômicos, políticos e ideológicos que atravessam uma determinada política institucionalizada. Estes vetores, por se realizarem implici- tamente ao processo de execução das políticas, constroem mediações complexas que apontam os valores ideológicos, os interesses econômicos e a perspectiva política objetivada na realização dos serviços expressos nas políticas sociais.

Desta forma, a execução de um determinado serviço, pode apontar tanto para a garantia da cidadania, quanto para a não cidadania, que, em última instância, contribui ou não para a formação de um determinado tipo de sujeito de direitos. Os componentes que reiteram a não cidadania constroem na representação popular e na realidade concreta o sujeito sem direito, que fica a mercê da "boa vontade" dos governantes brasileiros. É assim que a pobreza tende a ser enfrentada no Brasil, pois ao subir de "status" da condição natural para a condição de problema social, esta passa a incomodar a sociedade, sem conseguir transpor a condição de problema que incomoda, tendo em vista que suas formas de enfrentamento são construídas a partir do não reconhecimento dos pobres enquanto cidadãos.

Não reconhecidos como cidadãos, e, portanto, como sujeitos sociais na interlocução política nos momentos de confronto social, são excluídos de sua cidadania, são percebidos como bagunceiros, arruaceiros, desordeiros, que reclamam o que não tem direito, pois não contribuem para a construção do Brasil moderno. Como conseqüência, o que os pobres tendem a receber são serviços que, pela sua natureza, forma e conteúdo, objetivam prioritariamente o controle de uma "massa de desordeiros" que está incomodando a tranqüilidade social.

São os pobres, figura clássica da destituição. Para eles, é reservado o espaço da assistência social, cujo objetivo não é elevar condições de vida, mas minorar a desgraça e ajudar na miséria. Esse é o lugar dos não-direitos e da não-cidadania. É o lugar no qual a pobreza vira 'carência', a justiça se transforma em caridade e os direitos, em ajuda a que o indivíduo tem acesso não por sua condição de cidadania, mas pela prova de que dela está excluída (Ibid, p. 22).

O pobre torna-se o carente, que não precisa de justiça por não ser cidadão e, portanto, não tem direitos a serem assegurados, precisa sim da caridade alheia e da ajuda que o governo quiser lhe destinar. A expropriação a que é submetido é deslocada da questão econômica e desviada da compreensão de justiça e de direito, convergindo para explicações a-históricas e apolíticas da pobreza.

O discurso oficial sobre a pobreza apesar de modernizar-se não perde sua perspectiva de individualização do problema e nem de longe a compreende como contradição eminente do sistema econômico. Assume assim novas formas de apresentar-se, para evidenciar a preocupação governamental em erradicar a pobreza do país. 
A passagem da exclusão-inclusão não é instantânea e nem se faz de uma só maneira. E a inclusão, também, pela própria fragmentação dos programas sociais, se dá a partir de uma necessidade instituída. Com isto, a própria fragmentação é uma forma de não dar conta de todas as particularidades, de todas as esferas de necessidades de carências das pessoas (SPOSATI, 1986, p. 75).

O pobre vestido com a indumentária do carente e necessitado passa a ser visto como um indivíduo que possui carências que são reconhecidas pelo Estado em "doses homeopáticas", a partir dos conflitos sociais, e assim o indivíduo passa a ser visto não como sujeito de direitos, mas por meio da tipificação de suas carências sociais, em que seu reconhecimento e acesso se realiza por meio dessas tipologias. A identidade do indivíduo pobre, do destituído, vai escapando de suas mãos e este deixa de ter um rosto, uma singularidade, para ter um estereótipo definido pelas tipologias definidas nos programas sociais de atendimento ao indivíduo em situação de vulnerabilidade. Nesse processo, o indivíduo é recortado em toda a sua extensão e passa a ser o carente, o infrator, o abandonado ou em situação de risco $^{(1)}$ o imigrante, o idoso, homem de rua, etc.

Essa fragmentação, além de reforçar o não direito, apresenta um lado tão nocivo quanto o primeiro por meio do processo ideológico de inculcações das carências fragmentadas, ao ponto de criar uma identidade social nos indivíduos a partir destas carências. Desta forma, o acesso dos indivíduos a determinados serviços se realiza tanto por estarem destituídos das condições dignas de existência e sobrevivência, quanto por assumirem também a condição de carentes que necessitam de ajuda. Por isso, o reforço da fragmentação nas políticas de enfrentamento da pobreza aponta a instituição de estereótipos que manifestam uma lógica apresentada como determinista, longe de uma compreensão histórica dos fenômenos sociais. Assim, a fragmentação propriamente dita e as generalizações ideológicas acerca do pobre tendem a construir equívocos teóricos e metodológicos na compreensão e no trabalho com o fenômeno da pobreza.

No plano da fragmentação, os critérios de elegibilidade, via de regra, sustentam-se a partir de tipificações estabelecidas em que o indivíduo deve assumir o estereótipo do necessitado que deve ser atendido pelo programa, para dele fazer parte. Sendo comum ainda, a separação hierárquica dos necessitados, para se retirar àquele que mais necessita do serviço prestado. Diante desta perspectiva, estar incluído em um determinado programa social passa a ser um privilégio para poucos entre a imensidão de pobres. No entanto, estes "bem-aventurados" vivem numa corda bamba, pois ao se deslocarem um milímetro dos critérios exigidos são desligados dos mesmos programas que os reconheceram como habilitados ao recebimento do atendimento institucional. É clássica a tensão das mães ligadas a programas para crianças subnutridas, que todo mês sentem-se aliviadas ao constatarem na balança que seu rebento não atingiu o peso que o colocaria ao lado dos "bem-nutridos", habilitando-as assim a receberem por mais um mês a cesta alimentar.

$\mathrm{Na}$ perspectiva das generalizações, estas impedem que se compreendam as formas de estratificação social e a sociabilidade dos diferentes estratos sociais, assim como impede a construção de metodologias que atendam as especificidades da população vulnerabilizada. As generalizações tanto podem pautar-se numa lógica determinista como num romantismo-utópico que acredita numa metodologia abrangente que não leve em consideração as especificidades deste fenômeno social.

Nessa linha de reflexão, é possível inferir que a fragmentação, o privilégio, a hierarquia, a ajuda e outros elementos estão presentes na cotidianidade da execução das políticas sociais em diversas formas de enfrentamento da pobreza que mediam todo o processo de inclusão e exclusão dos serviços expressos nas políticas sociais. Desta forma, ao ser usuário das políticas de enfrentamento da pobreza o indivíduo é atingido tanto pela forma, quanto pelo conteúdo destes programas, que repercutirão nele em sua identidade social complexa. Portanto, as políticas de enfrentamento da pobreza podem ter uma penetração significativa nas dimensões objetiva e subjetiva do fenômeno pobreza, e como tal atingem objetiva e subjetivamente os indivíduos atendidos por estas.

\section{A indiferença com a pobreza}

Para refletirmos sobre a constituição de uma cultura da indiferença com a pobreza, e, por conseguinte, com a desigualdade na sociedade brasileira, usaremos o concurso do conceito de habitus precário criado por Jessé Souza (2003) para explicar o fenômeno da subcidadania e da indiferença com a pobreza em sociedades de modernização periférica. E assim, tentaremos agregar novos aspectos sobre a investigação da sociabilidade em sociedades afetadas pela moder-

\footnotetext{
(1) Denominações utilizadas pela Fundação do Bem Estar Social do Pará, em seus programas assistenciais para a execução das Políticas Sociais do Estado do Pará, no período 1987/1992.
} 
nização periférica como também refletir sobre componentes que podem estar sendo reproduzidos nas ações institucionais de atendimento realizado pelas políticas sociais.

Aspectos estes, que podem colaborar para compreender a harmonia que sintoniza os atores que "praticam" uma subcidadania em sua complexidade e em suas contradições e assim reproduzem uma indiferença com a pobreza.

\section{Do Habitus ao Habitus Precário}

O conceito de habitus foi cunhado em sua acepção mais contemporânea por Pierre Bourdieu. Apesar de não ter sido o primeiro a usar esta terminologia, Bourdieu (2000) destaca que "os utilizadores da palavra habitus se inspiravam numa intenção teórica próxima" (p. 62) da dele "que era a de sair da filosofia da consciência sem anular o agente na sua verdade de operador prático de construções de objecto" (p. 62). A argumentação do autor francês sobre o habitus parte do reconhecimento de que "as estruturas cognitivas não são formas de consciência, mas disposições do corpo" (p. 117). Desta forma, identifica que os diversos reclames à ordem no mundo em sociedade só podem funcionar "como tais para aqueles que estão predispostos a percebêlos, e que reanimam disposições corporais profundamente enraizadas, que não passam pelas vias da consciência e cálculo" (p. 117).

Esta percepção de Bourdieu (2000) recoloca em parte a compreensão sobre a ação histórica do homem, uma vez que esta, além de seu estado objetivado, se presentifica em "seu estado incorporado, que se tornou habitus" (p. 82). A compreensão da história incorporada como habitus, identifica a percepção de que a noção de habitus poderia revelar características identitárias comuns a cada classe social. Daí porque, conforme Bourdieu (1997, p. 21), "A cada classe de posições corresponde uma classe de habitus (ou de gostos) produzidos pelos condicionamentos sociais associados à condição correspondente".

Por isso mesmo "os habitus são diferenciados, mas são também diferenciadores" (Bordieu, 1997, p. 22), porque operam distinções que marcam fronteiras invisíveis - embora objetificadas nas disposições dos espaços sociais em que os indivíduos atuam, pois operam como signos distintivos profundamente arraigados naqueles que reproduzem os traços que os tornam reconhecíveis, devido seus habitus incorporados e que também são reconhecedores dessas mesmas marcas em outros habitus. É assim, que o habitus encerra uma hexis corporal (Bordieu, 1998) que se manifesta nas diversas expressões de agir do corpo no espaço social em que este se encontra. Isto quer dizer que o modelo de agir, de falar e outros, está em correspondência direta com a história individual e coletiva a que o indivíduo foi sujeito e sujeitado. Esta história, embora não retorne como tempo histórico, fica registrada nos corpos dos indivíduos e se reproduz em diversas manifestações desses corpos.

Essa reprodução da história nas práticas sociais vivificadas pelos corpos dos indivíduos afirma e reafirma, via de regra sem a consciência das origens dos atos, o conjunto hierarquizador e classificador das disposições dos corpos no tempo e no espaço em sociedade. Portanto, os diversos habitus podem revelar, por meio das práticas objetivadas dos indivíduos, conjuntos de elementos históricos que ficaram depositados e sedimentados em seus corpos como marcas "naturais" que ditam sua história e se fazem reconhecer na história dos outros. Em suma, por meio dos habitus objetivados nas práticas sociais, os indivíduos reconhecem e são reconhecidos por outros habitus objetivados. E ainda, conhecem e desconhecem aqueles corpos que fazem parte, ou não, que tem ligação, ou não, com a história criadora dos seus próprios habitus.

É neste ponto da inflexão de habitus presente em Bourdieu que Souza (2003) apresenta uma discussão que propõe recolocar o conceito de habitus. Sua reflexão pretende acrescentar "um caráter histórico mais matizado inexistente na análise bourdieusiana, portanto, uma dimensão genética e diacrônica à temática da constituição do habitus" (p. 165). Daí porque sua argumentação caminha no intuito de ultrapassar um conceito genérico de habitus que serviria a leituras "específicas de classe em um contexto sincrônico" (p. 165).

A proposta de Souza (2003) articula a reflexão de Bourdieu a "uma teoria objetiva da moralidade" (p. 164). A reflexão do autor aponta na proposição de diferentes habitus para permitir a apreensão de uma dinâmica histórica que matize "as mudanças fundamentais na estrutura econômico-social" (p. 165) com as suas implicações sobre a constituição dos habitus estruturantes e estruturados pelas diferentes práticas sociais. Práticas estas, realizadas pelos diversos grupos sociais que produzem e mantém o movimento histórico da própria realidade social. Assim, a dinâmica histórica que produz mudanças de caráter econômico, político e social, necessariamente, remete a um largo processo de socialização que se espraia consistente e firmemente para toda a sociedade em um determinado período temporal. É uma socialização que se fixa e se expande com o intuito de produzir uma aprendizagem coletiva, para afirmar e reafirmar os novos condicionantes da dinâmica histórica que traduz as características da qualidade das relações formadoras e formadas pelas classes constituidoras de uma dada sociedade.

Nesse aspecto, é inevitável não deixarmos de destacar 
a importância de Elias (1993, 1994) em suas obras sobre o Processo Civilizador que desmonta qualquer leitura estática da formação da sociedade ocidental moderna. Em seus estudos ficam evidentes os processos que mostram a sociedade ocidental moderna sendo constituída e construída desde as mais variadas expressões de sociabilidade humana. Em resumo, seus estudos revelam que o "life way" que vivemos surge a partir de uma socialização ampla que nos envolve e nos ensina a sermos contemporâneos do tempo em que vivemos ${ }^{(2)}$.

Portanto, sermos contemporâneos do tempo em que vivemos, implica em aprendermos e dominarmos os códigos classificadores e hierarquizadores das diferentes ações humanas sobre nós e que, por nós, podem e devem ser reproduzidas para manter os condicionantes que sustentam esses mesmos códigos. Por isso, para sermos contemporâneos de uma época e de uma sociedade, precisamos ter um habitus capaz de nos "guiar" frente ao mar de códigos e estímulos que nos atinge na vida cotidiana. Esse habitus incorporado e generalizado permite que possamos (cor) responder às diferentes manifestações da sociabilidade cotidiana, pois nos capacita a (re)agir de forma "adequada" frente as diversas situações que se apresentam a nós.

Segundo Souza (2003) a proposta bourdieusiana de habitus, a rigor é o que denomina de habitus primário, pois os "esquemas avaliativos e disposições de comportamento objetivamente internalizados, e 'incorporados', permite o compartilhamento de uma noção de 'dignidade' efetivamente compartilhada no sentido tayloriano" (p. 166). O habitus primário explicaria então a sedimentação do "reconhecimento social infra e ultrajurídico" (p. 166) da igualdade como regra e princípio das práticas sociais, uma vez que "Para que aja eficácia legal da regra de igualdade é necessário que a percepção da igualdade na dimensão da vida cotidiana esteja efetivamente internalizada" ( $p$. 166) e seja também compartilhada pelos indivíduos como estabelecida.

Daí porque o habitus primário está assentado e fixado como dado em grupos e sociedades cuja história compartilhada tenha produzido como forte referência a igualdade que é cultivada na sociabilidade dos corpos dos indivíduos formadores e formados nesses grupamentos humanos. O habitus primário traduz-se e é incorporado na sociabilidade diária que matiza a igualdade que valora e hierarquiza a relação do indivíduo com os outros indivíduos nas práticas sociais cotidianas. O habitus primário revela a instituição do valor da igualdade presentificado como expressão comportamental que se realiza nos e pelos corpos individuais e sociais. Desta forma, o conjunto hierarquizador no habitus primário surge como um a priori que está instituído, e que, ao ser praticado torna-se instituidor, pois se reafirma e se reproduz socialmente.

Não obstante, fazer parte de um espaço social em que o habitus primário está consolidado como marca identitária, implica em também saber a "dor e a delícia" das correspondentes cobranças que o reconhecimento de igualdade traz. Isto quer dizer que o "consenso valorativo transclassista" (SOUZA, 2003, p.166) que está presente na vida cotidiana, em que o habitus primário é formado e reproduzido, exige dos indivíduos a igual generalização das "pré-condições sociais, econômicas e políticas do sujeito útil, 'digno' e cidadão" (p. 167) que terá que "responder" aos reclames sociais que exigem dele uma vida produtiva e útil.

Por isso mesmo, Souza (2003) considera habitus precário como aquele que "seria o limite do habitus primário para baixo, ou seja, seria aquele tipo de personalidade e disposições de comportamento que não atendem as demandas objetivas" (p. 167) de uma sociedade marcada pela competitividade mercantil que requer (exige) do indivíduo uma atuação social produtiva e útil para que ele seja reconhecido como membro desta. Como exemplo o autor alerta que existem sociedades ocidentais modernas "como a alemã em que, já apresentam agora segmentos de trabalhadores e de pobres que vivem do seguro social" (p. 167), e que por assim dizer tem os traços de "um habitus precário".

Em estudo recente, Paugam (2003) destaca, a partir de sua análise da Renda Mínima de Inserção - RMI francesa, o surgimento do fenômeno "nova pobreza", com a "multiplicação dos empregos instáveis e grande aumento do desemprego prolongado, como também ao enfraquecimento dos vínculos sociais" (p.31) daquela realidade. Não obstante, o fenômeno da nova pobreza na Europa, o habitus precário "só ganha o estatuto de um fenômeno de massa permanente, em países periféricos como o Brasil" (SOUZA, 2003, p.167). No entanto, como fenômeno de massa, o habitus precário precisa estar associado a outros fenômenos que sustentam a sua "funcionalidade", pois "sem isso o caráter violento e injusto da desigualdade social se manifestaria de forma clara e a olho nu" (p.168).

Desta forma, uma personalidade formada por uma massa de trabalhadores incapazes de serem considerados produtivos e úteis precisa beber e estar embebida em um

\footnotetext{
(2) Aqui ser contemporâneo do tempo em que se vive é tratado no sentido estrito, pois se refere exclusivamente a estar sintonizado com os códigos de um determinado espaço e tempo social.
} 
"pano de fundo consensual acerca do valor diferencial dos seres humanos" (SOUZA, 2003, p. 168) que legitime a desigualdade como fato que é reconhecido e tratado "naturalmente". Esse pano de fundo destacado por Souza (2003, p. 169) é a "ideologia do desempenho" que, ao assentar-se em valores da meritocracia, se espraia e se consolida como aquela que "estimula e premia a capacidade de desempenho" e também "legitima o acesso diferencial permanente as chances de vida e apropriação de bens escassos".

A ideologia do desempenho funciona como uma liga que articula os indivíduos de forma atomizada, e por isso mesmo tem uma funcionalidade de largo alcance, pois o reconhecimento do desempenho individual sobrepõe-se aos processos coletivos e sociais reais. Como ideologia "ela é intransparente posto que 'aparece' à consciência cotidiana como se fosse efeito de princípios universais e neutros, abertos à competição meritocrática" (SOUZA, 2003, p.170). Portanto, esta ideologia legitima processos coletivos como se individuais o fossem, sustentando que o acesso dos indivíduos a bens e serviços produzidos socialmente decorressem da capacidade e do empenho individual de cada um $^{(3)}$.

Como o princípio básico do consenso transclassista é o princípio do desempenho e da disciplina (a fonte moral do self pontual para Taylor) passa a ser a aceitação e internalização generalizada deste princípio que faz com que a inadaptação e a marginalização destes setores possam ser percebidos, tanto pela sociedade incluída como também pelas próprias vítimas, como um "fracasso pessoal” (SOUZA, p. 171).

E assim o binômio reconhecimento e desconhecimento $^{(4)}$ fincam-se como o verificador e o justificador tanto do sucesso quanto do fracasso do desempenho do indivíduo, pois verifica e justifica os esforços positivos (ou negativos) do indivíduo e desconhece os fatores políticos, econômicos e socais que formam os condicionantes históricos em que "o desempenho do indivíduo" se realiza.

\section{O aprendizado da indiferença com a pobreza}

A proposição feita por Souza (2003) de articular habitus precário à ideologia do desempenho para compreender as especificidades da desigualdade presente em sociedades que são produtos da modernização periférica expõe a complexidade da convivência "naturalizada" entre concentração da riqueza e pobreza extrema.
Interessa-nos, nesse ponto, apresentarmos alguns elementos para contribuir em particular na reflexão sobre os processos de "aprendizagem" dessa "convivência naturalizada". Isto porque a formação do habitus precário, assim como a sedimentação da ideologia do desempenho são também resultantes de processos, via de regra, "naturalizados" e eclipsados à razão pragmática da vida cotidiana. Como resultantes de processos, existem injunções e valores intransparentes que cultivam o nascimento, o crescimento e a reprodução objetiva e subjetiva do habitus precário e da ideologia do desempenho. "A dimensão aqui é objetiva, subliminar, implícita e intransparente. Ela é implícita também no sentido de que não precisa ser linguisticamente mediada ou simbolicamente articulada" (SOUZA, 2003, p. 175).

No mundo objetivo em que são aradas as desigualdades sociais podem existir "acordos e consensos sociais mudos e subliminares, mas, por isso mesmo tanto mais eficazes que articulam, como que por meio de fios invisíveis, solidariedades e preconceitos profundos e invisíveis" (SOUZA, 2003, p. 175). A presença desses acordos mudos e subliminares, em sociedades periféricas "implica a existência de redes invisíveis e objetivas que desqualificam os indivíduos e grupos sociais precarizados como subprodutores e subcidadãos" (p. 177). Desta forma, cabe a nós indagarmos sobre os processos que revelam a existência dessas redes invisíveis e objetivas, e também como estas redes produzem a sua presença como fato instalado que, por existir como um $a$ priori aparentemente legitimado, tem a função de ensinar os passos da dança da subcidadania.

O autor destaca a importância de instituições fundamentais que ancoram a formação de habitus com "a percepção dos efeitos sociais de uma hierarquia atualizada de forma implícita e opaca" (p. 177) e "a identificação de seu potencial segregador e constituidor de relações naturalizadas de desigualdade em várias dimensões" (p. 178). Notadamente, no caso da sociedade brasileira, Souza (2003) reconhece nessas instituições fundamentais o mercado e o Estado, pois produzem uma "imposição objetiva, independente de qualquer intencionalidade individual" (p. 180) e que, portanto, universalizam um conjunto de valores que passam a ser adotados como fatos dados na sociedade. Como fatos dados, esses conjuntos de valores adquirem funcionalidade pela sua própria dimensão pré-reflexiva, pois compõem o habitus dos próprios indivíduos.

\footnotetext{
(3) Pode-se fazer referência a vários ditos populares que estão sustentados nessa ideologia: "Deus ajuda a quem cedo madruga"; "Deus dá asas a quem não sabe voar", e outros.

(4) Albuquerque (1986) propõe a presença articulada dessas duas formas de relação em seus estudos sobre os processos de sociabilidade em instituições totalitárias.
} 
A reflexão sobre o ancoramento institucional aponta uma direção interessante, uma vez que traduz a relevância que as instituições tem sobre o processo de aprendizagem no qual os indivíduos ficam sujeitos. Desta forma, tanto o habitus precário, quanto a ideologia do desempenho, precisam ser introjetados para sedimentarem-se como história objetiva no corpo e como valores naturalizados, respectivamente. Assim, por mais fortes que sejam as instituições mercado e Estado não prescindem de outras instituições que existem na sociedade brasileira. Estas instituições realizam, em conjunto e complementarmente, as imposições objetivas que atuam sobre a sociedade ${ }^{(5)}$ sistematicamente. Portanto, não existe a formação de habitus sem ancoramento institucional, todavia, esse ancoramento nos parece difuso, uma vez que o indivíduo em sua trajetória histórica relaciona-se com diferentes instituições que, apesar da diversidade delas, contribuem para que ele incorpore um conjunto de valores legitimados pela coletividade.

Dito de outra forma, as instituições são elementos que mediam a relação indivíduo x coletividade, ou seja, são os espaços privilegiados em que se processam as injunções entre o singular e o genérico, produzindo as condições objetivas e subjetivas (no espaço social das instituições ${ }^{(6)}$ ) à introjeção dos valores e o correspondente aprendizado das condutas e ações associadas a estes. Esses valores moldam o arcabouço de normas e parâmetros que compõem a hierarquia valorativa internalizada pelo indivíduo como "fatos naturais". Nos termos bourdeusianos, de acordo com as posições que o indivíduo vai ocupando no campo social, ele se relaciona com um conjunto diverso de instituições que mediam os processos de introjeção dos valores sociais que compõem o seu habitus.

Aos moldes do processo de sedimentação apontado por Berger e Luckmann (1985), as experiências de sociabilidade do indivíduo com as instituições em que ele se relaciona em sua trajetória de vida, processam uma internalização profunda dos valores hierarquizantes que farão parte da sua disposição identitária (BOURDIEU, 1998). Essa disposição identitária revelada no habitus do indivíduo manifesta-se opaca justamente por ser apreendida como a resultante de um processo considerado natural. Não obstante, foi produzida no conjunto das sociabilidades cotidianas ${ }^{(7)}$ das instituições que o indivíduo esteve incluso. Por isso mesmo, mergulhado em um cotidiano absorvente que requer a presença do ser humano inteiro, o indivíduo, via de regra, queda-se as exigências da cotidianidade, pois fica prisioneiro de um pragmatismo perseverante.

Por sua vez, esse pragmatismo perseverante da cotidianidade tem uma tendência à totalização, uma vez que pretende tornar-se referência a partir da hierarquia valorativa imputada na sociabilidade da vida diária, na "maneira como as pessoas se reúnem dentro ou fora das instituições, como elas se relacionam com as pessoas em geral" (D'INCAO, 1996, p.136). E assim, pretende impor-se como parâmetro e padrão de interpretação e prática social que se espraia a outras esferas sociais da vida do indivíduo.

Como padrão internalizado, o conjunto valorativo incorporado no habitus tende a orientar a relação do indivíduo com o mundo factual em sua sociabilidade diária. Desta maneira, o indivíduo pode ficar prisioneiro do imediato ${ }^{(8)}$ das relações cotidianas, que por fazerem parte do mundo factual, oculta as mediações ontológicas dos fenômenos produzidos pelo homem. Na sociabilidade cotidiana se processam dois fenômenos complementares: um, diz respeito a incorporação afirmativa dos valores institucionais como aqueles que devem ser apreendidos como as referências que orientam as práticas sociais (vale lembrar que essa incorporação não é linear e não se realiza sem contradições, daí porque as instituições organizam sanções para controlar aqueles que "desrespeitam" os valores do grupo).

O outro, diz respeito a reafirmação dos valores institucionais frente a situações que põem a prova o compromisso e o grau de integração do indivíduo à instituição.

As coisas que se tornam alvos morais nossos não o fazem somente em virtude do fato de estarmos comprometidos de facto com elas. Essas coisas tem de ter um status mais forte de modo que a vejamos como exigindo, requerendo ou pedindo esse compromisso (TAYLOR, 1995, p. 50).

\footnotetext{
(5) Não podemos esquecer que, conforme Berger e Luckmann (1985), não existe alguém totalmente institucionalizado, como alguém sem nenhuma institucionalização.

(6) Para Bourdieu (2000, p. 137) o espaço social "é um espaço de relações o qual é tão real como um espaço geográfico no qual as mudanças de lugar se pagam em trabalho, em esforços e, sobretudo em tempo (ir de baixo para cima e guindar-se, trepar e trazer as marcas e os estigmas desse esforço).

(7) Segundo Heller (1972, p. 17) “a vida cotidiana é a vida do homem inteiro; ou seja, o homem participa na vida cotidiana com todos os aspectos de sua individualidade, e de sua personalidade".

${ }^{(8)}$ Quanto ao conceito de imediato é "importante observar que, na totalidade concreta, nenhum objeto - ou fato - é realmente imediato (isto é: nenhum objeto se põe ao pensamento sem que seja produto, resultado de mediações); o que ocorre é que, para o sujeito cognoscente, ele pode apresentar-se assim. A imediaticidade é uma função da consciência teórica e não um dado ontológico" (FALCÃO; NETTO, 1987, p. 81).
} 
O fenômeno da reafirmação ocorre porque as instituições objetivadas em coisas ou fatos "checam" o compromisso do indivíduo à instituição por serem, em muitos casos, alvo de uma "avaliação forte" com "tal natureza que, se cessarmos de desejá-lo nós seríamos considerados insensíveis, rudes ou moralmente perversos" (TAYLOR, 1995, p. 50). Em sociedade, por diversas vezes o indivíduo é requerido a se posicionar e defender não só o seu status social como a instituição em que esse status adquiriu os seus contornos.

Entretanto, o processo em que se realizam esses dois fenômenos complementares produz aquilo que Bourdieu (1998) denomina de magia do ato de instituição. Essa magia oculta, sob o manto da "naturalização", um fenômeno que foi constituído socialmente, daí porque esse processo produz um duplo engano. O primeiro engano está no fato de reconhecer a avaliação forte como uma exigência valorativa que está a priori na própria instituição objetivada. Este engano identifica a instituição como um ente autônomo capaz de se auto-valorar e impor seu valor sobre o indivíduo. O outro engano está em reconhecer que esta exigência se realiza sobre o indivíduo em uma relação direta entre a instituição e o indivíduo, quando tanto a instituição quanto o indivíduo são produzidos coletivamente.

Esta clareza é importante para recolocar a relação instituição x indivíduo, pois frente aos fenômenos da realidade factual que exigem "uma avaliação forte" estará em jogo, inevitavelmente, uma relação indivíduo x coletivo e coletivo $\mathrm{x}$ coletivo. É por isso mesmo que a hierarquia internalizada precisa ser pré-reflexiva, uma vez que identifica os valores e as normas como parte do "jeito de ver a vida", da personalidade, e ao mesmo tempo desconhece a origem social e coletiva desses mesmos valores ${ }^{(9)}$. Assim:

É o homem - como ser histórico e social e com a sua atividade prática - que cria os valores e os bens nos quais se encarnam, independentemente das quais só existem como projetos ou objeto ideais. Os valores são, pois, criações humanas, e só existem e se realizam no homem e pelo homem (VÁSQUEZ, 1995, p. 126)

Desta maneira a complexidade do processo de encarnação dos valores torna-o ainda mais opaco e invisível, uma vez que se realiza no seio das instituições, que promovem $\mathrm{o}$ ancoramento institucional e a força vinculante (SOUZA, 2003) que sedimenta a hierarquia internalizada no e pelo próprio indivíduo. Ocorre que os "valores encarnados" fazem parte da consciência do indivíduo que, por sua vez aparecem como algo pessoal, individualizado. No entanto:

Existindo sob a forma de imagens ideais surgidas no cérebro do homem em decorrência da interação com a realidade que a rodeia, a consciência representa um reflexo subjetivo da realidade... A consciência, sendo assim o reflexo subjetivo da realidade objetiva, é a unidade do que depende do sujeito, do estado de seu sistema nervoso, de sua experiência individual, de sua situação social, de suas condições de vida, etc... e do que não depende dele, mas que é condicionado pela realidade ambiente e a reflete" (CHEPTULIN, 1982, p. 98).

Uma vez que esteja sedimentado o esquema valorativo, a força vinculante objetifica o conjunto hierárquico incorporado no habitus do indivíduo como fenômeno de longa temporalidade. E assim, este conjunto hierárquico torna-se opaco em relação a sua própria historicidade, mas se vivifica no ancoramento institucional ${ }^{(10)}$ pelas recorrentes "lembranças" que a nossa disposição no espaço social nos remete. Portanto, somos constante e sistematicamente lembrados, pelo espaço social que nos encontramos (e obviamente pelas disposições que ocupamos neste), do conjunto valorativo hierarquizante que ordena e opera nossas práticas sociais.

Alguns exemplos sobressaem-se a respeito desse processo: via de regra os indivíduos que adotam alguma referência religiosa ao adentrarem no ambiente físico de uma dada religião reconhecem naquele espaço vários códigos que parece que os "induzem" a adotarem determinados comportamentos em detrimento de outros. Desta forma, a sociabilidade ampla em que estamos inseridos é, em grande parte, responsável pela aprendizagem tanto das regras de convivência social em geral, quanto das regras "naturalizadas" da convivência dentro da desigualdade social. Obviamente que a convivência dentro de relações de desigualdade social, mesmo que estas relações pretendam a se impor como "naturais", não ocorre sem tensões e conflitos.

Todavia, a sedimentação dos valores formadores do habitus precário, cimentado pela "ideologia do desempenho", funciona com fundações profundas que prendem o indivíduo a "operadores simbólicos" que, internalizados, valoram e justificam a posição social deste na escala da desigualdade em que está disposto. Esses

(9) Os valores são fenômenos ontológicos justamente por serem formados por inúmeras mediações que operam a sua construção e constituição (ver Vázquez, 1995).

${ }^{(10)}$ Isto quer dizer que mesmo que a história como tempo passado de uma dada instituição esteja morta como tempo, não está “como espaço; o momento passado já não é nem voltará a ser, mas sua objetivação não equivale totalmente ao passado, uma vez que está sempre aqui e participa da vida atual como forma indispensável à realização social” (SANTOS, 2004, p. 14). 
operadores simbólicos produzem apelos incontestes que questionam e avaliam as práticas do indivíduo com o intuito de verificarem se estas estão em correspondência com as disposições identitárias deste (BOURDIEU, 1998).

Um exemplo de operador simbólico é o sentimento de vergonha que em sua manifestação revela que o indivíduo é orientado "por uma pauta do que é certo e do que é errado, do que é apropriado e do que não é apropriado" (MARTINS, 1999, p.10) frente a diferentes situações sociais da vida em sociedade. Por isso mesmo "A vergonha e o embaraço não são mais regras externas, tornam-se "naturais" (PIMENTA e OLIVEIRA, 1999, p.21) e assim, operam a favor da "correção" das condutas do indivíduo que, frente a uma dada situação social, agiu contrariando os padrões de comportamento legitimados pelo coletivo de um grupo dado.

A vergonha é expressão de um débito a ser pago, o que foi maculado precisa ser reparado. É como forma de pagamento desse débito com a comunidade que, algumas vezes, o coadjuvante tenta reparar as situações que não ocorreram devidamente (PIMENTA; OLIVEIRA, 1999, p. 25).

O processo civilizador (ELIAS, 1993, 1994) da sociedade ocidental produziu uma ampla difusão da vergonha como sentimento coletivo que se manifesta individualmente. Sua difusão para e a sua incorporação pelos indivíduos opera uma auto-vigilância profunda que cobra práticas sociais consideradas corretas, e também a expressão de padrões e status sociais "mínimos" para todos os indivíduos em sociedade. Daí porque a força da vergonha, em muitas situações, é tamanha que paralisa os indivíduos "atacados" por ela.

Pois não há nada que enfraqueça nem que paralise mais que a vergonha. Ela altera na raiz, deixa sem meios, permite toda espécie de influência, transforma em vítimas aqueles que sofrem, daí o interesse do poder em recorrer a ela e a impô-la; ela permite fazer a lei sem encontrar oposição, e transgredi-la sem temor de qualquer protesto. É ela que cria o impasse, impede qualquer desmistificação, qualquer enfrentamento da situação (FORRESTER, 1997, p.12).

A vergonha discutida por Forrester (1997) pode também expor como as instituições operam contradições, uma vez que mediam a incorporação de um conjunto de valores que "guiam" o indivíduo para a realização de seu futuro, e se revelam, em muitos casos, incapazes de tornar realidade os mesmos valores prometidos. Como o processo de incorporação dos valores se realiza coletivamente, (mas sedimenta-se individualmente), tende-se a ocorrência do deslocamento das causas que gestaram e construíram essa incorporação. E assim, o indivíduo torna-se o centro e o responsável tanto do seu sucesso quanto de sua desgraça individual, "restando-lhe" a satisfação egoísta de uma conquista ou a vergonha de um fracasso ${ }^{(11)}$ pessoal.

Por isso mesmo a vergonha pode expor para o próprio indivíduo o fato de estar agindo "inadequadamente" tanto em relação a uma conduta legitimada no grupo, quanto em relação a estar mal situado no contexto do espaço social que se encontra ${ }^{(12)}$.

A expressão da vergonha é o sentimento do "olhar do outro", que faz o indivíduo sentir vontade de sumir, de esconder-se das vistas dos outros, enterra-se (PIMENTA, OLIVEIRA, 1999, p. 153).

Corrêa (1998) ao estudar meninas - mulheres que vivem nas ruas, em contato com um grupo que circulava pelo Ver-o-Peso ${ }^{(13)}$ identifica que o trajeto destas pelo complexo comercial se realizava com desenvoltura. Todavia, quando se encontravam fora de seu espaço social (considerados pelos informantes como "suas casas"), elas assumiam posturas diferentes daquelas realizadas no ambiente que conviviam cotidianamente. Para a pesquisadora o cenário em que se realizaram as entrevistas (diferente do ambiente considerado pelas informantes como "suas casas"); se constituía em um espaço em que as referências simbólicas eram distantes daqueles que "permitiam" que as informantes "se encontrassem" e "soubessem como agir". Por isso:

[...] em lugar dos gestos largos; gestos extremamente contidos. No lugar das risadas altas e longas; risos tímidos e silenciosos. No lugar de braços e pernas querendo "abraçar" ruas e pessoas; braços e pernas cruzadas, acompanhadas de uma cabeça baixa, procurando a todo momento, esconder as marcas e cicatrizes em sua face. Neste cenário o copo miúdo de A.C. perde sua altivez, ele era apenas um corpo que não fazia parte daquele cenário, mas que por ele foi curvado formando uma espécie de concha da qual só se libertaria fora dali (CORRÊA, 1998, p.53).

Outro forte operador simbólico que matiza as relações daqueles que se encontram em condições de desigualdade social é o sentimento de gratidão "esperado" e "exigido"

(11) Sennett (2000) aponta que na atualidade existe a expansão de uma sensação de deriva que corrói o caráter do homem atual pelo fato deste não encontrar as bases objetivas de relações de longo prazo para a permanência e a reprodução de valores de lealdade, solidariedade e de auto-reconhecimento social.

(12) Não seria por isso que a vergonha deixa o indivíduo "sem jeito", com a sensação de "inadequação" comportamental e/ou espacial, de não saber o que falar ou agir frente a situações sociais deslocadas do seu cotidiano?

(12) Entreposto comercial da cidade de Belém do Pará desde a época do Brasil Colônia que foi incorporado como identidade geográfica, social e cultural da cidade, tornando-se símbolo turístico. 
daqueles que recebem ajuda de outros. Como a relação de ajuda implica em um mascaramento de uma relação de tutela, as situações em que a ajuda se expressa, via de regra, induzem a incorporação de um sentimento de gratidão que opera uma, ou várias, contraprestações de ações daquele que recebeu a ajuda para aquele que a prestou.

No campo da política a gratidão opera fortes dependências nos indivíduos que recebem "doações" de bens e serviços devido a "boa vontade" dos governantes empenhados em associarem e vincularem suas imagens de político as ações do governo que representam. Na mecânica da gratidão constituída no seio das relações de desigualdade social, os bens e serviços inscritos como direitos dos cidadãos são ressignificados como favores que tutelam (TELLES, 1999) os indivíduos que os acessam.

Desta maneira, no mundo dos corpos moldados nas relações que constroem os habitus precários, os direitos de cidadania transmutam-se em ajuda e no favor subalternizador que tendem a inscrever fortemente nos indivíduos o sentimento de gratidão. Este, por sua vez, incorporado, opera a "necessidade" de um comprometimento, em maior ou menor grau dependendo do "tamanho" do sentimento de gratidão, do tutelado para com o doador da ajuda. No esteio da reflexão da dança da subcidadania e da indiferença com a pobreza, a melodia que embala a seqüência dos movimentos corporais executados pelos indivíduos se realiza de maneira ritmada em uma coreografia que foi apreendida em um amplo aspecto de sociabilidades que os indivíduos produziram e que foram também por elas produzidos. Os acordes dos ritmos da subcidadania revelam que existem várias danças e diferentes dançantes que desempenham papéis devidamente inscritos em seus habitus precários.

É assim que os fatos reveladores de uma situação de desigualdade social, de dominação e exploração são devidamente coreografados por dominantes e dominados, exploradores e explorados, com "variações de passos e ritmos". Esses passos e ritmos são tão "naturalizados" que a maioria já sabe como dançar. Um forte exemplo desta ação é a situação do trabalho infantil doméstico em que tanto o indivíduo que explora a mão de obra infantil, quanto a família do infante explorado reconhece naquela situação uma boa ação e uma melhor oportunidade de vida, respectivamente.

A constituição do habitus precário é a resultante de um amplo processo de mediações conduzidos e formados no seio de diversas e diferentes instituições sociais a que os indivíduos se relacionam. Desta forma, as instituições presentes na trajetória histórica dos indivíduos, são os cenários que propiciam as configurações pelas quais as danças da subcidadania e da indiferença com a pobreza são apreendidas.

Certamente podemos falar na dança em termos gerais, mas ninguém imaginará como uma estrutura fora do indivíduo ou como uma mera abstração. As mesmas configurações podem certamente ser dançadas por diferentes pessoas, mas, sem uma pluralidade de indivíduos reciprocamente orientados e dependentes, não há dança. Tal como as demais configurações sociais, a da dança é relativamente independente dos indivíduos específicos que a formam aqui e agora, mas não de indivíduos como tais (ELIAS, 1994, p. 250).

Assim, as danças da subcidadania são produzidas e apreendidas no conjunto das relações sociais que matizam a desigualdade social. Por isso, estas danças apresentam os contornos dos salões em que elas foram coreografadas e treinadas. Esses salões, por sua vez, são espaços sociais que, independente de serem públicos ou privados, desempenham uma nítida função social. Ao mesmo tempo em que sustentam os condicionantes sociais que produzem a incorporação dos habitus precários, funcionam como campos de treinamento que realizam dois movimentos combinados.

Conviver no mundo significa essencialmente ter um mundo de coisas interposto entre os que nele habitam em comum, como uma mesa se interpõe entre os que se apresentam ao seu redor; pois, como intermediário, o mundo ao mesmo tempo separa e estabelece uma relação entre os homens (ARENDT, 1991, p. 62).

Portanto os salões de treinamento das danças da subcidadania relacionam e separam os indivíduos que serão os atores das coreografias apresentadas na vida cotidiana em sociedade. E por assim dizer, vão configurando e formatando as relações de aproximação e separação como se fossem fatos "naturais" para todos os dançantes dos salões da sociedade.

MACIEL, C. A. B. Inequality and the indifference with the poverty. Rev. Ter. Ocup. Univ. São

Paulo, v.19, n. 1, p. 1-11, jan./abr. 2008.

ABSTRACT: This text discusses on the process of learning of the social behavior of the indifference with the poverty in a context of social inequality. It considers the poverty as a social phenomenon produced historically that it has objective and subjective expressions. It especially adopts the reflections of Pierre Bourdieu and Jessé Souza on habitus for the elaboration of the analysis produced concerning the institution of the indifference of the poverty.

KEY WORDS: Social inequity. Poverty. Habits. 
MACIEL, C. A. B. Desigualdade e a indiferença com a pobreza. Rev. Ter. Ocup. Univ. São Paulo, v. 19, n. 1, p. 1-11, jan./abr. 2008.

\section{REFERÊNCIAS}

ALBUQUERQUE, J. A. G. Instituição e poder. $2^{\mathrm{a}}$ ed. Rio de Janeiro: Graal, 1986.

ARENDT, H. A condição humana. $5^{\text {a }}$ ed. Rio de Janeiro: Forense Universitária, 1991.

BERGER, P.; LUCKAMANN, T. A construção social da realidade. $12^{\mathrm{a}}$ ed. Petrópolis: Vozes, 1985.

BOURDIEU, P. Razões práticas. Campinas: Papirus, 1996.

BOURDIEU, P. A economia das trocas lingüísticas. $2^{\mathrm{a}}$ ed. São Paulo: Editora da UNESP, 1998.

BOURDIEU, P. O campo econômico: a dimensão simbólica da dominação. Campinas: Papirus, 2000 b.

BOURDIEU, P. O poder simbólico. $3^{\mathrm{a}}$ ed. Rio de Janeiro: Bertrand Brasil, 2000

CHEPTULIN, A. A dialética materialista: categorias e leis da dialética. São Paulo: Alfa - Ômega, 1982.

CORRÊA, I. M. X. de A. A rosa tatuada: um estudo antropológico sobre a linguagem nos corpos de meninas - mulheres que vivem nas ruas - mimeo. Dissertação [Mestrado], UFPA, 1998.

D'INCAO, M. A. Modos de ser e de viver: a sociabilidade urbana. In: TEMPO social n ${ }^{\circ}$. São Paulo: USP, 1992.

D'INCAO, M. A. Sentimentos modernos. São Paulo: Brasiliense, 1996.

ELIAS, N. O processo civilizador. v. 2. Rio de Janeiro: Zahar, 1993.

ELIAS, N. O processo civilizador. v. 1. Rio de Janeiro: Zahar, 1994.

FALCÂO, M. do C.; NETTO, J. P. Cotidiano: conhecimento e crítica. São Paulo: Cortez, 1987.

FORRESTER, V. O horror econômico. São Paulo: UNESP, 1997.
HELLER, A. O quotidiano e a história. Rio de Janeiro: Paz e Terra, 1972.

LOWY, M. Ideologias e ciências sociais. $2^{\mathrm{a}}$ ed. São Paulo: Cortez, 1985.

MARTINS, J. de S. et al.. Vergonha e decoro na vida cotidiana da metrópole. São Paulo: Hucitec, 1999.

MARX, K. Textos econômicos. São Paulo: Mandacaru, 1990.

MIAGUSKO, E.; FERREIRA, L. M. P. Circunstantes e coadjuvantes na interação social: o poder da vergonha. In: MARTINS, J. de S. Vergonha e decoro na vida cotidiana da metrópole. São Paulo: Hucitec, 1999.

PAUGAM, S. Desqualificação social: ensaio sobre a nova pobreza. São Paulo: Cortez/EDUC, 2003.

PIMENTA, M. M.; OLIVEIRA, R. C. O Constrangimento do corpo na interação social: o nojo. In: MARTINS, J. de S. Vergonha e decoro na vida cotidiana da metrópole. São Paulo: Hucitec, 1999.

SANTOS, M. Pensando o espaço do homem. $5^{\text {a }}$. ed. São Paulo: Edusp, 2004.

SENNEDT, R. A corrosão do caráter. Rio de Janeiro: Record, 1999.

SOUZA, J. A construção social da subcidadania. Belo Horizonte: UFMG; Rio de Janeiro: IUPERJ, 2003.

TAYLOR, C. Argumentos filosóficos. São Paulo: Loyola, 2000.

TELLES, V. da S. Direitos sociais: afinal do que se trata? Belo Horizonte: UFMG, 1999.

TELLES, V. da S. A cidadania inexistente: incivilidade e pobreza. Um estudo sobre a família na grande São Paulo. São Paulo, 1992. Tese [Doutorado] - Departamento de Sociologia da Universidade de São Paulo.

VÁZQUEZ, A S. Ética. $15^{\mathrm{a}}$ ed. Rio de Janeiro: Civilização Brasileira, 1995. 